\title{
Research on Seedling Seeding Machine of Multi-functional Film Membrane Direct-Inserted and Hole-Seeding for Ginseng
}

\author{
Lili Huang ${ }^{1}$, Xiaobin Liu ${ }^{1}$, Foshu Luo ${ }^{3}$, Wenxiang Lian ${ }^{1}$, Languang $\mathrm{Lu}^{2} \&$ Yanjing $\mathrm{Li}^{1}$ \\ ${ }^{1}$ School of Automotive Engineering, Lanzhou Institute of Technology, Lanzhou, Gansu, China \\ ${ }^{2}$ Automotive Research Institute, Tsinghua University, Beijing, China \\ ${ }^{3}$ Mechanical Engineering College, Xi'an Shiyou University, Xi'an, Shanxi, China \\ Correspondence: Lili Huang, School of Automotive Engineering, Lanzhou Institute of Technology, 01 \\ Gongjiaping Donglu, Qilihe District, Lanzhou, Gansu 730050, China. Tel: 86-189-1904-8877. E-mail: \\ huanglili_lily@126.com
}

Received: November 6, 2019

Accepted: December 7, 2019

Online Published: January 15, 2020

doi:10.5539/jas.v12n2p92

URL: https://doi.org/10.5539/jas.v12n2p92

The research is financed by Gansu Province Department of Education program under the Higher Education Scientific Research Gansu of China Project entitled "Design and Research on the Film Membrane Seeding Machine of Multi-functional Hole Broadcasting Seeding and Direct-inserted Ginseng Seedling”, Item Number: 2017A-109.

\begin{abstract}
The planter is designed for solving the problem of Ginseng seedlings, which not only meets the requirements of small particle seed metering, but also realizes zero-speed direct-inserted sowing, and can intelligently as well as automatically control the working performance of the whole machine, adapting to various sowing environmental conditions. The equipment is designed for seeding and breeding of the Ginseng seedlings, which is also possible to multiply the various grain-type plants by changing the size of the seeding device. The power system uses a non-polluting battery as power source, and the power is distributed to every moving mechanism by a speed reduction mechanism. The total mechanical equipment is light in weight, making it easy to operate and lowering the cost. The outstanding feature of this research is that the designed product can detect the depth of the seeding hole according to the control system in real-time. In order to prevent the ground conditions from affecting the depth of the hole, the suspension system is designed as a controllable spring suspension to avoid the leakage and invalid seeding. The stiffness and height of the suspension are more adapted to the sowing conditions and meet the sowing requirements.
\end{abstract}

Keywords: ginseng, film mulching, zero-speed direct-insertion, seedling, multi-purpose planter

\section{Introduction}

Ginseng is a traditional tonic medicine in China. It has the functions of supplementing the vital energy, strengthening the spleen, improving the lungs, enhancing immunity, dilating blood vessels, reducing blood pressure, improving microcirculation, and enhancing hematopoietic function etc. Besides, it affects the decline of white blood cells caused by chemotherapy and radiotherapy. At present, the sowing method of Ginseng seedlings has been popularly spread domestically and internationally. The seeds are mixed with the same amount of fine soil and spread in the seedbed, which is then compacted so that the seeds can be closely combined with the soil. The general seeding amount is 50 to $60 \mathrm{~kg} \mathrm{hm}^{-2}$ (Baogang, 2010). According to the market research, the traditional method mainly relies on manual labour without any machinery, which leads to low seeding efficiency, high labor intensity and low seeding rate. The scale of planting area is small and the low output could not meet market demand that resulted in expensive Ginseng production cost. In addition, it is hard to cultivate a high variety of Ginseng due to the fact that theseedling cultivation has not been improved, especially for some areas that are relatively dry in the year, the reproduction and its industrial chain is restrained. Therefore, a new type of Seedling Seeding Machine of Multi-functional Film Membrane Direct-inserted and Hole-seeding for Ginseng was applied for the first time. 
In the agricultural market, a variety of crop-type punch seeding planters, such as cotton planters, grain seeders, vegetable planters and others have been developed. The development of the hole-seeding planter mainly focused on the hole-forming principle, structure of the hole-forming device, the relationship between seeding and the hole-forming device. For the small grain seeder, there are obvious deficiencies in sowing precision, sowing reliability and sowing machine life. On this basis, there is currently no plastic film seeding planter for direct-injection seedlings (Chenglin \& Chenhua, 2014).

The multi-functional film-drilling Ginseng seedling seeding machine has better drilling and sowing performance, meanwhile, it has simple structure and convenient operation. It is very important to be suitable for various topography that can significantly improve the growth environment of Ginseng, such as surface temperature, humidity and light intensity (Mengchun, 2012). The advantage of current design is that it can help reducing the evaporation of surface water, increasing the yield and variety quality of Ginseng, expanding the planting area of Ginseng seedlings, improving work efficiency (Jixin, 2013), and promoting the development of the Chinese herbal medicine industry.

\section{Structure and Parameters}

\subsection{Machine Structure}

As shown in Figure 1, the multi-functional film-covering direct-inserted Ginseng seedling seeding machine under the condition of film-mulching sowing machine includes car handle, electric motor, reducer, battery, frame, chain 1 , sprocket 1 , sprocket 2 , sprocket 3 , Shaft 1 , sprocket 4 , chain 2 , chain 3 , sprocket 5 , sprocket 6 , front axle, sleeve, bolt, spring, ground wheel, camshaft, cam, roller, movable cone duckbill, pushrod, hole forming rod, guide rod B, screw nut, screw motor, guide rod A, connecting rod 1, eccentric wheel 1 (crank A), rear axle, chute, type hole, seeding slider, row spacing control ruler, seedbox, connecting rod 2, eccentric wheel 2 (crank B), seed shaft, sprocket 7, chain 4, UCP bearing, etc.

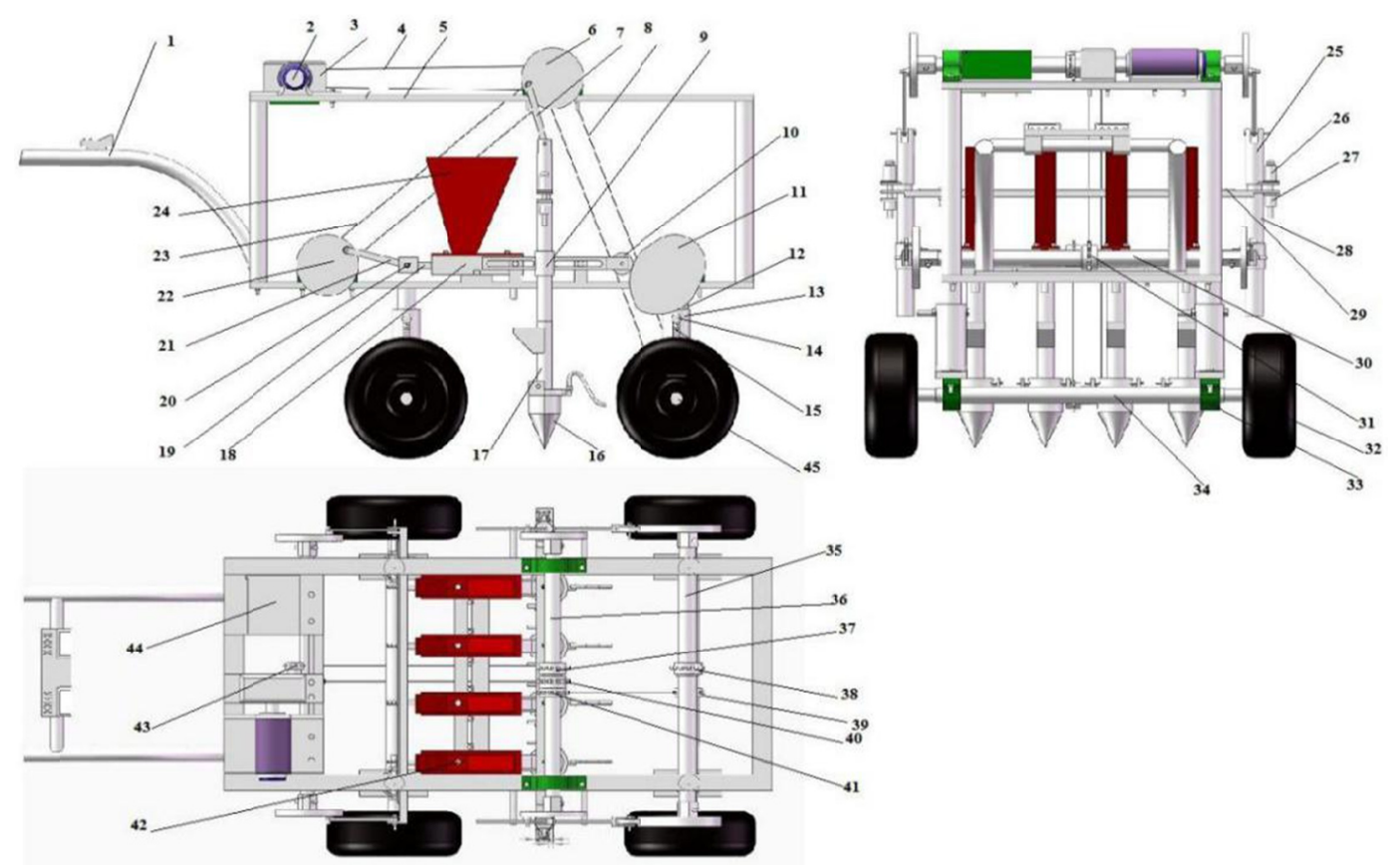

Figure 1. Schematic diagram of multi-functional film-covered and in-line type Ginseng seedling planter

Note. 1-car handle; 2-motor; 3-reducer; 4-chain 1; 5-frame; 6-eccentric 1 (crank A); 7-connecting rod 1; 8-chain 2; 9-push rod; 10-roller; 11-cam; 12-chain 3; 13-sleeve; 14-bolt; 15-spring; 16-active tapered duckbill; 17-hole forming rod; 18-chute; 19-seed slider; 20-slider connector; 21-connecting rod; 2 22-eccentric 2 (Crank B); 23-chain 4; 24-Seedbox; 25-guide rod A; 26-screw motor; 27-screw nut; 28-guide rod B; 29-row spacing control ruler; 30-seed shaft; 31-sprocket 6; 32-ground wheel; 33-UCP bearing; 34-rear axle; 35-camshaft; 36-shaft 1; 37 -sprocket $1 ; 38$-sprocket $4 ; 39$-sprocket $5 ; 40$-sprocket $2 ; 41$-sprocket 3;42-type hole; 43-sprocket 7; 44-battery; 45-front axle. 
The machine adopts a maintenance-free battery and the electric motor as the power source of the whole machine system. The battery drives the motor to run. The motor accelerates the torque through the reducer and then transmits the power to the shaft 1 by the chain drive. The rotary motion of the shaft-driven eccentric 1 (crank A) is converted into a vertical reciprocating motion of the hole-forming rod through the connecting rod to realize continuous seeding requirements. The power on the shaft is transmitted to the front axle by the chain, and to the camshaft through the chain by the front axle of the vehicle. The rotary motion of the camshaft driving the cam to be converted into the left and right linear reciprocating motion of the pushrod. The zero-speed seeding of the planter in the vertical direction can be achieved by a combination between the crank guide mechanism and the cam mechanism. The power is transmitted to the seeding shaft by the shaft 1 through the chain, and the seed shaft drives the eccentric wheel 2 (crank B) on the shaft to rotate, meanwhile the seed slider is driven by the connecting rod to linearly reciprocate in the sliding groove to realize the seeding process.

In the beginning, the seed slider has a cylindrical type hole facing the bottom of the seedbox, which is designed according to a certain amount of seed volume. The seed falls into the hole through the self-weight, and then makes the seed slider to be pushed in the seeding chute, and it means the seeding task is completed by the self-weight of the seed falling into the hole forming rod.

\subsection{Technical Indicators}

The structural parameters of the whole film-coated direct-inserted seeding Ginseng seedling planter are shown in Table 1.

Table 1. Technical parameters of intelligent film-covered and direct-inserted Ginseng seedling planter

\begin{tabular}{ll}
\hline Item & Parameter \\
\hline Dimensions $(\mathrm{mm} \times \mathrm{mm} \times \mathrm{mm})$ & $2385 \times 1238 \times 1350$ \\
Drive Wheel Diameter $(\mathrm{mm})$ & 400 \\
Number of Hole Spreaders & $1-8$ \\
Working Speed $\left(\mathrm{m} \mathrm{s}^{-1}\right)$ & 0.2 \\
Seeding Line Spacing $(\mathrm{mm})$ & $40-400$ \\
Adjustable Depth $(\mathrm{mm})$ & $0-100$ \\
Plant Spacing $\left(\mathrm{mm}^{-1}\right.$ & $40-400$ \\
Crank Speed $\left(\mathrm{r} \mathrm{min}^{-1}\right)$ & $300-30$ \\
\hline
\end{tabular}

\section{Performance Design}

\subsection{Direct-Inserted Hole-Forming Device}

Direct-inserted seeding means the seeds passing through the vertically inserted hole forming rods and directly entering the proper position of the soil during the whole sowing process at one time (Xiaoguang, Chunxi, \& Feng, 1993). To achieve vertically insert and out, it is necessary to ensure that the absolute speed of the hole-forming device in this direction is zero (Jiantuo, Wuyun, \& Yanhua, 2010a). The straight-inserted seeding device designed with a combination of a crank guide mechanism and a cam mechanism to control the hole forming rod (Hongan \& Shilu, 2001). The straight inserting sowing device is mainly composed of an eccentric wheel, a connecting rod, a guide rod, a push rod, a roller, a cam, a duckbill, and a hole forming rod in this paper. The schematic diagram of straight inserting sowing is shown in Figure 2. 


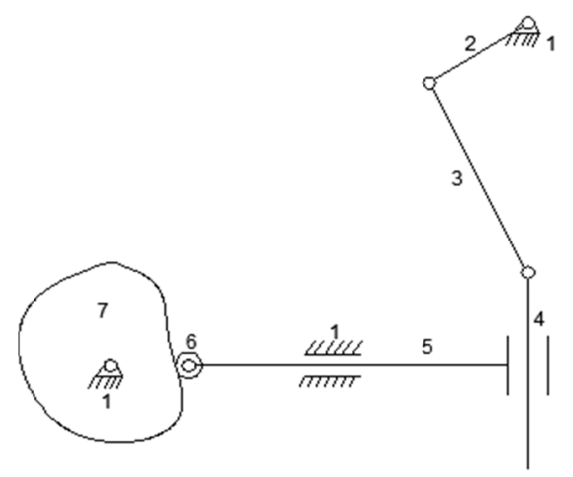

Figure 2. Schematic diagram of straight inserting sowing

Note. 1-rack; 2-crank; 3-a connecting rod; 4-guide rod; 5-push; 6-roller; 7-cam.

The parameters of the mechanism are determined by the planter functional requirements (Linwei, Wuyun, Wei, Rongbin, Bingbang, \& Fei, 2017), such as crank length $\mathrm{L}_{2}=80(\mathrm{~mm})$, connecting rod length $\mathrm{L}_{3}=200(\mathrm{~mm})$, guide rod $\mathrm{L}_{4}=600(\mathrm{~mm})$, push rod $\mathrm{L}_{5}=300(\mathrm{~mm})$. According to above parameters and applied mechanical principles, the completed structure of the straight inserted cavitation device is shown in Figure 3.

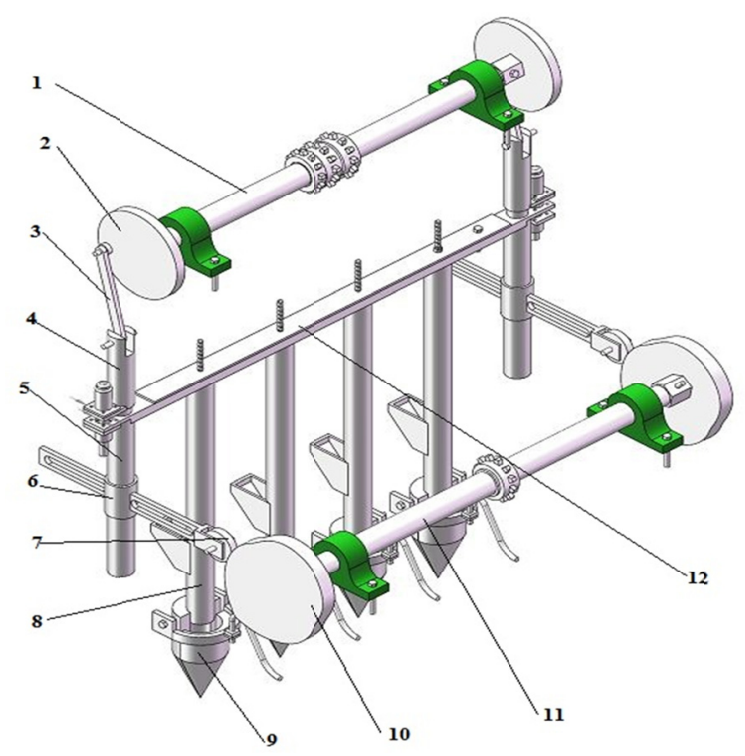

Figure 3. Structure schematic diagram of the straight inserted cavitation device

Note. 1-cavity axis; 2-eccentric wheel 1 (crank A); 3-connecting rod 1; 4-guide rod A; 5-guide rod B; 6-push rod; 7-roller; 8-hole forming rod; 9-active cone duckbill; 10-cam; 11-camshaft; 12-row spacing control ruler.

\subsection{Seeding Device}

During the sowing process, it is needed to take the Ginseng seeds out from the seedbox and put into the hole forming rod. This process is achieved by a crank slider mechanism (Lianggui \& Minggang, 2006). The seeding device is mainly composed of eccentric crank, seedbox, crank, connecting rod, slider, seed-picking shaft, chute and type hole, as shown in Figure 4. The ground wheel drives the seed-picking shaft to rotate through the chain, and the seed-picking shaft drives the eccentric wheel (crank) to rotate on the shaft, the connecting rod make the slider do linear reciprocating motion in the chute to realize the seed-picking process (China Academy of Agricultural Mechanization Sciences, 2007).

The cylindrical shaped hole on the slider is designed according to a certain volume of seeds. In initial state, the shaped hole is opposite to the bottom of the seed box; when picking the seeds, after the seed falls into the hole through dead gravity, it is pushed into the seed drop tube by the slider. Then, all the seeds falls into the hole rod 
to complete this task. The biggest characteristic or the most innovative is strong universality for seeds with diameter less than $1 \mathrm{~mm}$, which will solve the long-standing problem of precisely picking seed amount for small seeds while sowing.

Mechanical design manual software is often used in the design of linkage mechanism, which can analyze and simulate the movement of planar linkage mechanism. It is very simple and practical. Therefore, the software of mechanical design manual is used to simulate the movement of seed harvesting device. First, selecting the design type as the design of crank slider mechanism, and then inputing some initial parameters as stroke $(\mathrm{H}=160$ $(\mathrm{mm}))$, stroke speed ratio coefficient $(\mathrm{K}=1)$ to get the corresponding component geometric parameters as crank $(\mathrm{a}=80(\mathrm{~mm}))$, the link $(\mathrm{b}=160(\mathrm{~mm}))$, and the offset $(\mathrm{e}=0)$. The simulation results are consistent with the expected design results.

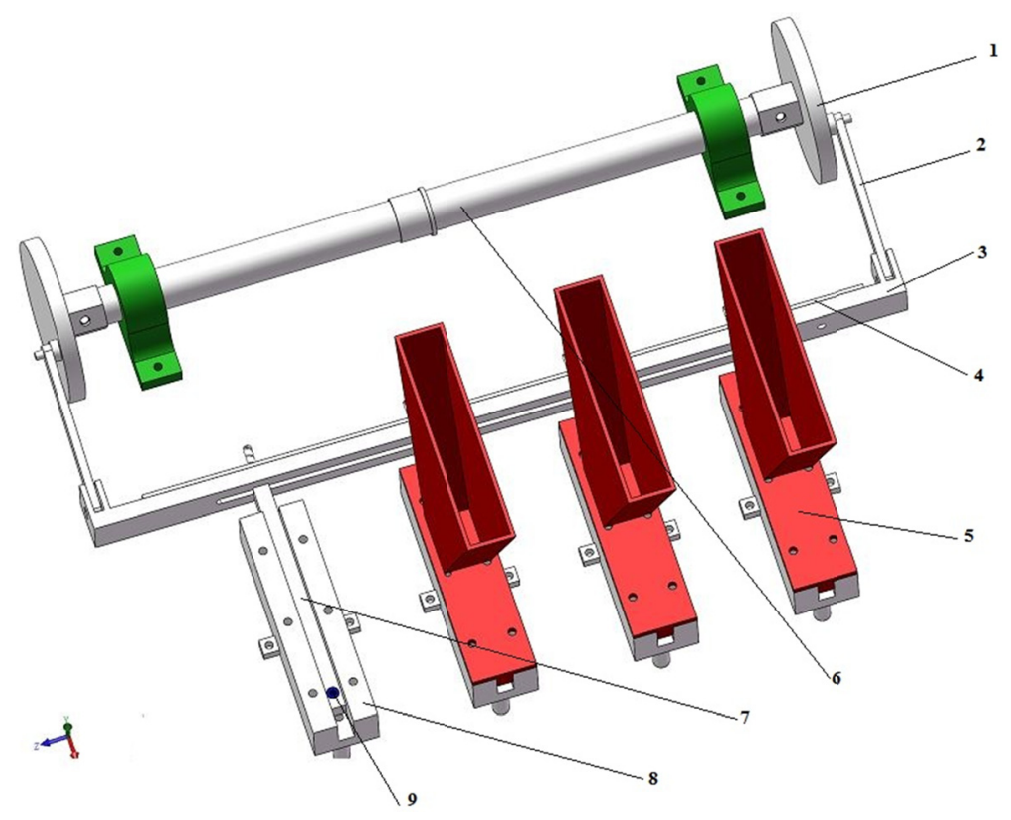

Figure 4. Structure schematic diagram of seed-picking shaft, device

Note. 1-eccentric crank; 2 crank B; 2-connecting rod; 3-slider joint; 4-row spacing control rule; 5-seedbox; 6-seed-picking shaft; 7-seed-picking slider; 8-chute; 9-type hole.

\subsection{Slider and Type Hole}

A step hole is processed on the slider for the type hole, according to mechanical principles designed the slider structural schematics as shown in Figure 5. The structural diagram of the type hole is shown in Figure 6. The inner diameter of the type hole (D) is determined by the total volume of seeds (V1) required for each hole. According to the empirical value and Equation (1), about $3534\left(\mathrm{~mm}^{3}\right)$ Ginseng seeds should be sown in each hole so that the seedbed environment can well meet the growth of this crop. V1 and V2 must be equal (V1 = V2) as Equation (3) in order to ensure accurate sowing. The inner diameter of the type hole (D) can be calculated by Equation (2), such as $\mathrm{D}=15(\mathrm{~mm})$, the inner hole height of the type hole $(\mathrm{h}), \mathrm{h}=20(\mathrm{~mm})$. Other size is design to ensure its mechanical strength as the 3D structure shown in Figure 7. Applying the theory can design different type hole size according to the needs and establish a type hole library that would realize the variety of crop seeds and the generalization of tools, expanding the application range of the seeder.

$$
\begin{gathered}
V_{1}=N \cdot V \\
V_{2}=h\left(\frac{D}{2}\right)^{2} \pi \\
V_{1}=V_{2}
\end{gathered}
$$


In Equations (1)-(3), $V_{1}$ : Total crop volume $\left(\mathrm{mm}^{3}\right) ; V_{2}$ : Inner hole volume $\left(\mathrm{mm}^{3}\right) ; N$ : Number of seeds required per hole; $V$ : Volume of a seed $\left(\mathrm{mm}^{3}\right) ; D$ : Inner diameter of the type hole $(\mathrm{mm}) ; h$ : Inner hole height of the type hole $(\mathrm{mm}), h=20$.
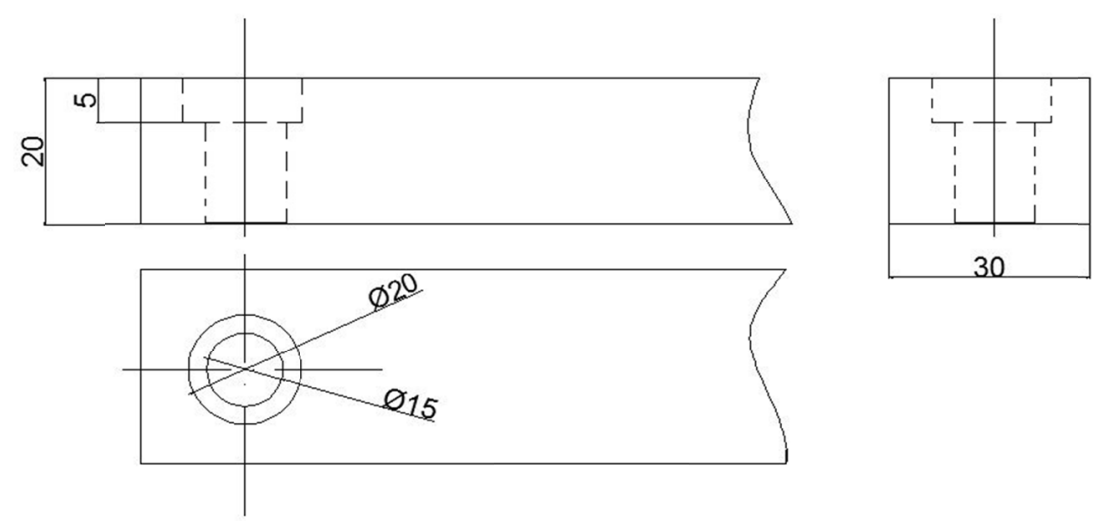

Figure 5. The slider structural schematicas

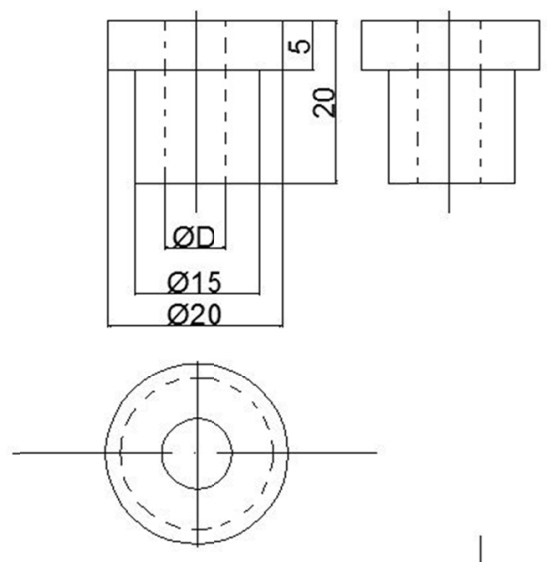

Figure 6. The structural diagram of the type hole

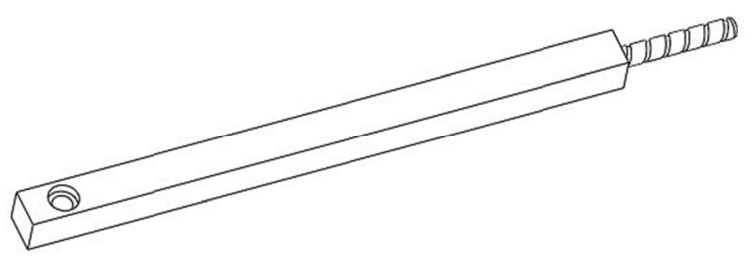

(a) 3D Slider

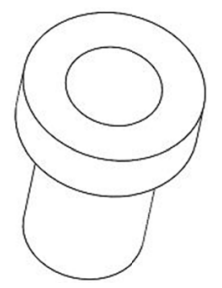

(b) 3D type hole

Figure 7.3D schematic diagram of the slider and the type hole

\subsection{Row Spacing Adjustment Device Design}

The plant spacing of the seeder can be adjusted by the control ruler. Taking a four-hole sowing tube as an example, as shown in Figure $8 \mathrm{~b}$, the first hole is a positioning hole, and the other four control plant spacing. The rod of the hole forming device and the slider in the picking seeds device are connected to the row spacing control ruler by bolts. By adjusting the distance between the four holes the plant spacing can be changed, as shown in Figure $8 \mathrm{a} . \mathrm{L}_{1}$ is the distance between the positioning hole and the spacing control hole, it is a fixed value, $\mathrm{L}_{1}=$ $100(\mathrm{~mm}) . \mathrm{L}_{2}$ is the distance between the spacing control holes, and this distance is a variable. $\mathrm{L}$ is actual row 
spacing (mm), which satisfies the Equation 4. To meet the requirements of generalization, the plant spacing control ruler library is designed to meet the requirements of different plant spacing sowing. The selection is based on the Equation 4.

$$
L_{2}=L
$$

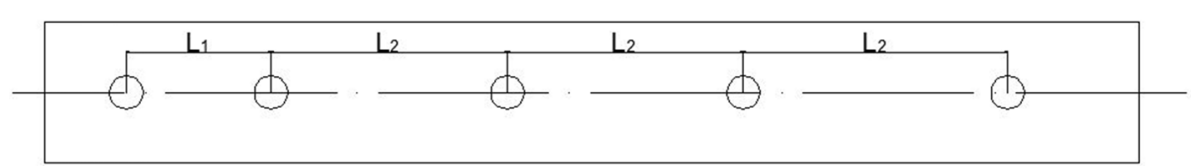

Figure 8a. 2D Plant spacing control ruler

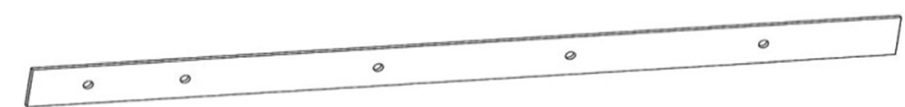

Figure 8b. 3D Plant spacing control ruler

\subsection{Cavitation Device}

The hole forming device is mainly realized by the duckbill. Currently, the duckbill commonly has two kinds of wedge shape and cone shape. The performance of the tapered duckbill is better than the wedge shape (Wei $\&$ Jianmin, 2009), so the tapered duckbill is applied in the device, whose schematic diagram as shown in Figure 9.
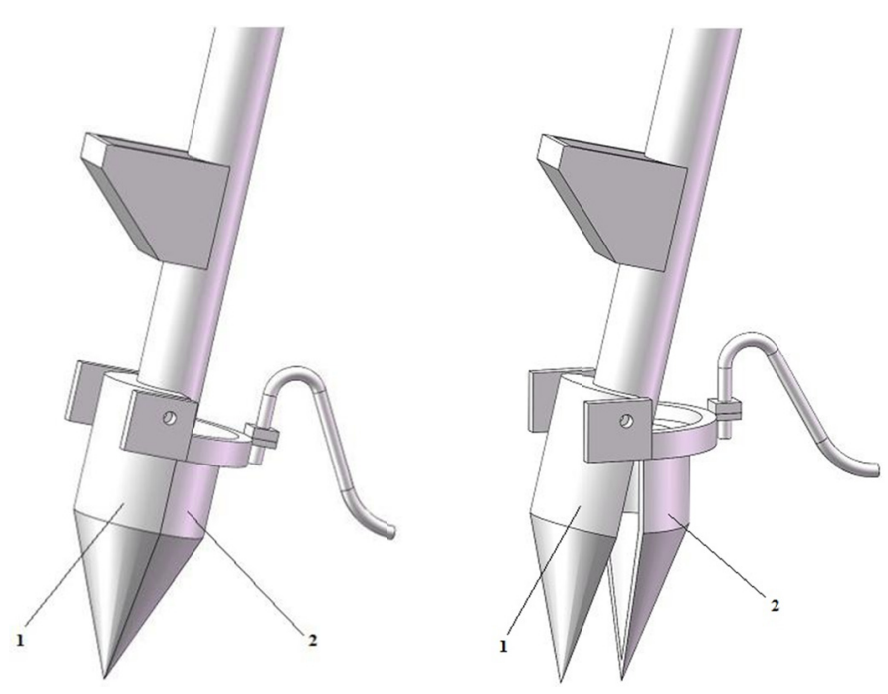

Figure 9. Schematic diagram of the tapered duckbill

Note. 1-hole forming rod (fixed cone duckbill); 2-active tapered duckbill.

\subsection{Depth Adjustment Device}

Due to the different sowing environment and the flatness of the ground, Cavitation rod needs to be adjusted in depth. The principle is to adjust the depth by changing the length of the guide rod. The depth adjustment is mainly completed by the ball screw device, see Figure 10. The flatness of the ground is collected by the sensor, supplying signal to the motor, which drives the ball screw to rotate. The guide rod is fixed to the screw nut under the action of the lead screw by bolt connection and maked a linear motion to automatically control the depth adjustment. 


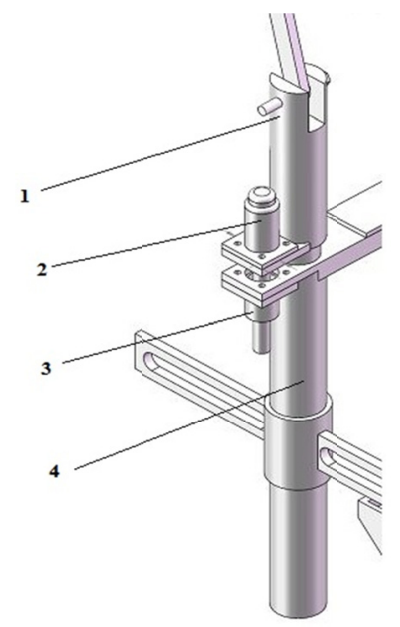

Figure 10. Schematic diagram of the depth adjustment device

Note. 1-guide rod A; 2-screw motor; 3-screw nut; 4-guide rod B.

\subsection{Shock Absorbing Device}

In order to better adapt to various road conditions and reduce the rigid impact of the whole machine to extend the service life of the whole machine, a shock absorbing device is designed. The damping device is mainly composed of a frame, a spring, a sleeve, a bolt, etc., as showed in Figure 11.

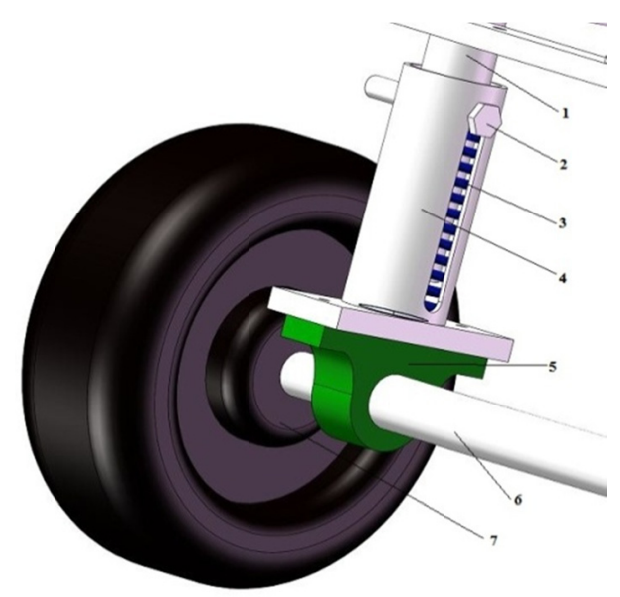

Figure 11. The shock absorbing device

Note. 1-frame; 2-pin; 3-spring; 4-suspension; 5-UCP bearing; 6-axle; 7-ground wheel.

\subsection{Relationship Between Plant Spacing and Seeder Speed}

The plant spacing $(s)$ can be 40 to $400(\mathrm{~mm})$. the best seeder speed $(v)$ is $0.2\left(\mathrm{~m} \mathrm{~s}^{-1}\right)$ for Ginseng, the time $(t)$ of the straight inserting hole-forming device reciprocating up and down once in a sowing cycle when the seeder moved one $S$ plant spacing distance, which calculated by Equation 5 is about 0.2 to $2(s)$. They are satisfied with this relationship between $\mathrm{t}$ and the speed of crank $\mathrm{A}\left(n_{p}\right)$ is Equation $6, n_{p}$ is 30 to $300\left(\mathrm{r} \mathrm{min}^{-1}\right)$. Also the speeds of picking seeds device and the cam link rod is the same as the crank A. It is known that the ground wheel speed is $0.2\left(\mathrm{~m} \mathrm{~s}^{-1}\right)$ with a $200(\mathrm{~mm})$ radius. So according to Equation 7 and Equation 8 calculating the wheel speed is $9.6\left(\mathrm{~m} \mathrm{~s}^{-1}\right)$, and taking an integer value $10\left(\mathrm{~m} \mathrm{~s}^{-1}\right)$ as the result. When the seeder speed is a constant value, the relationship among plant spacing, motor speed and the speed of crank A is shown in Table 2.

$$
\begin{gathered}
s=v t \\
n_{p}=1 r \cdot t^{-1}
\end{gathered}
$$




$$
\begin{gathered}
v=R \omega \\
\omega=2 \pi n
\end{gathered}
$$

Table 2. Velocity relationship of moving members in power transmission system

\begin{tabular}{lllll}
\hline $\begin{array}{l}\text { Motor speed } \\
n_{d}\left(\mathrm{r} \mathrm{min}^{-1}\right)\end{array}$ & $\begin{array}{l}\text { Plant spacing } \\
s(\mathrm{~mm})\end{array}$ & $\begin{array}{l}\text { Seeder speed } \\
v\left(\mathrm{~m} \mathrm{~s}^{-1}\right)\end{array}$ & $\begin{array}{l}\text { Wheel speed } \\
n_{c}\left(\mathrm{r} \mathrm{min}^{-1}\right)\end{array}$ & $\begin{array}{l}\text { Speed of crank A } \\
n_{p}\left(\mathrm{r} \mathrm{min}^{-1}\right)\end{array}$ \\
\hline 1200 & 40 & 0.2 & 10 & 300 \\
1080 & 80 & 0.2 & 10 & 270 \\
960 & 120 & 0.2 & 10 & 240 \\
840 & 160 & 0.2 & 10 & 210 \\
720 & 200 & 0.2 & 10 & 180 \\
600 & 240 & 0.2 & 10 & 150 \\
480 & 280 & 0.2 & 10 & 120 \\
360 & 320 & 0.2 & 10 & 90 \\
240 & 360 & 0.2 & 10 & 60 \\
120 & 400 & 0.2 & 10 & 30 \\
\hline
\end{tabular}

It can be seen from Table 2 that the crank speed and motor speed is changing with the plant spacing increasing, the motion of crank A and motor speed slow down as the plant spacing increases. The changing relation is linear and conforms to the law of motion power transmission. The relation among plant spacing, motor speed and the speed of crank A in the Table 2 is showed intuitively as shown in Figure 12, which is a graphical representation of the data in the Table 2 as a lookup-tab diagram to select the motor speed and the crank speed corresponding to the plant spacing. For example, when the plant spacing $(s)$ is $40(\mathrm{~mm})$, the motor speed is $1200\left(\mathrm{r} \mathrm{min}^{-1}\right)$ and the crank speed is $300\left(\mathrm{r} \mathrm{min}^{-1}\right)$; And when the plant spacing is $360(\mathrm{~mm})$, the motor speed is $240\left(\mathrm{r} \mathrm{min}^{-1}\right)$ and the crank speed is $60\left(\mathrm{r} \mathrm{min}^{-1}\right)$.

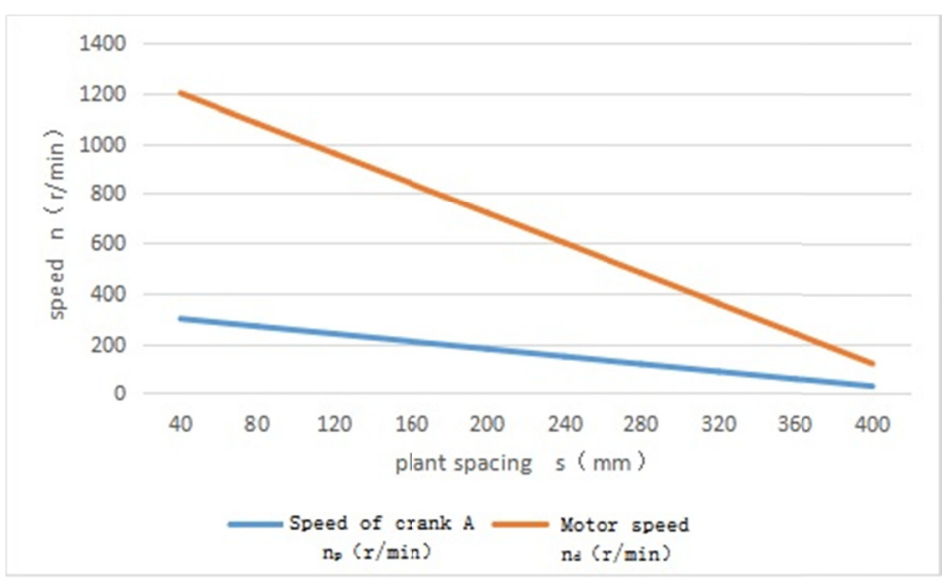

Figure 12. Relationship between plant spacing and moving members

\subsection{Motor Selection}

For precisely sowing small seeds like ginseng, choosing the right motor can ensure that the speed of ground wheel and sowing speed match, so the choice of motor is particularly important. The seeder is a low speed and low power equipment with continuous operation to ensure its accuracy and quantitative. The transmission system should reduce transmission series to improve transmission efficiency and reduce operation cost as far as possible. Moreover, the total transmission ratio is not suitable to be too large, and the transmission with 2 to 3 series is more reasonable, so the motor with $1450\left(\mathrm{r} \mathrm{min}^{-1}\right)$ synchronous speed and $4(\mathrm{kw})$ mechanical power $\left(P_{d}\right)$ satisfying Equation 9 that is the best choice. $P_{e}$ is rated powerand of the motor which meets the following requirements: 
1) The rotation speed of the metering seed mechanism should be low, generally around $30 \mathrm{r} \mathrm{min}^{-1}$;

2) The power match with its speed;

3) With large starting torque, continuous operation and stable load, mostly adapting to dust.

$$
\begin{gathered}
P_{\mathrm{d}} \geq P_{\mathrm{e}} / \eta \\
\eta=\eta_{d} \cdot \eta_{l} \cdot \eta_{p}
\end{gathered}
$$

According to Zongze (2006) and Longchang, Zhian, and Xinzheng (2000), obtained $\eta_{d}=0.92, \eta_{l}=0.9, \eta_{p}=0.96$; calculated $\eta=0.8, P_{d} \geq 5 \mathrm{~kW}$ by Equation 10 . So the selection of the DC motor model is $Z_{2}-52$ and the basic parameters are shown in Table 3.

Table 3. Basic motor parameters

\begin{tabular}{llllllll}
\hline Type & $\begin{array}{l}\text { Rated power } \\
(\mathrm{kW})\end{array}$ & $\begin{array}{l}\text { Rated current } \\
(\mathrm{A})\end{array}$ & $\begin{array}{l}\text { Rated voltage } \\
(\mathrm{V})\end{array}$ & $\begin{array}{l}\text { Rated speed } \\
\left(\mathrm{r} \mathrm{min}^{-1}\right)\end{array}$ & Excitati mode & $\begin{array}{l}\text { Excitation voltage } \\
(\mathrm{V})\end{array}$ & $\begin{array}{l}\text { Excitation current } \\
(\mathrm{A})\end{array}$ \\
\hline $\mathrm{Z}_{2}-52$ & 6.5 & 59.5 & 115 & 1450 & Multiple & 115 & 2.98 \\
\hline
\end{tabular}

\section{Sports Performance Simulation Analysis}

Known parameters: crank speed $n=30\left(\mathrm{r} \mathrm{min}^{-1}\right)$, cam speed $n=30\left(\mathrm{r} \mathrm{min}^{-1}\right)$, planter forward speed $v=0.15(\mathrm{~m}$ $\left.\mathrm{s}^{-1}\right)$.

\subsection{Model Analysis}

In order to balance the horizontal speed when the machine is moving forward, the cam is designed as constant velocity motion (Han, Jue, \& Jinhua, 1983), to ensure that the absolute speed of the burrowing machine is zero, and to meet the demand of zero speed direct insertion. At the same time, in order to eliminate the rigid and flexible impact of cam motion, the displacement and speed of cam guide-bar should be continuous. Based on the above two conditions, the rule of cam motion is designed to modified constant velocity, which is to add a combined interharmonic curve as the transition curve when thrust and return phase of acceleration curve (Guoxun \& Zhengyang, 1990). The cam is rotated one turn, the cam rotation angle $\varphi$ and the push rod displacement function are shown as Equation 11. Follower stroke $\mathrm{h}=90(\mathrm{~mm})$, follower offset $\mathrm{e}=0(\mathrm{~mm})$, roller radius $\mathrm{R}_{\mathrm{T}}=25(\mathrm{~mm})$, push motion angle $\phi=150^{\circ}$, far angle of repose $\phi_{s}=30^{\circ}$, return movement angle: $\phi^{\prime}$ $=150^{\circ}$, near angle of repose $\phi_{s}^{\prime}=30^{\circ}$, base circle radius $\mathrm{R}_{0}=100(\mathrm{~mm})$.

$$
s=\left\{\begin{array}{l}
\frac{h}{3}\left(\frac{2 \varphi}{\phi}-\frac{1}{2 \pi}\left(\sin \frac{4 \pi \varphi}{\phi}\right)\right)\left(0 \leq \varphi<\frac{5 \pi}{24}\right) \\
\frac{h}{3}\left(\frac{4 \varphi}{\phi}-\frac{1}{2}\right)\left(\frac{5 \pi}{24} \leq \varphi<\frac{5 \pi}{8}\right) \\
\frac{h}{3}\left(1+\frac{2 \varphi}{\phi}-\frac{1}{2 \pi} \sin \frac{4 \pi \varphi}{\phi}\right)\left(\frac{5 \pi}{8} \leq \varphi<\frac{5 \pi}{6}\right) \\
90\left(\frac{5 \pi}{6} \leq \varphi<\pi\right) \\
h-\frac{h}{3}\left[\frac{2\left(\varphi-\phi-\phi_{s}\right)}{\phi^{\prime}}-\frac{1}{2 \pi} \sin \frac{4 \pi\left(\varphi-\phi-\phi_{s}\right)}{\phi^{\prime}}\right]\left(\pi \leq \varphi<\frac{29 \pi}{24}\right) \\
h-\frac{h}{3}\left[\frac{4\left(\varphi-\phi-\phi_{s}\right)}{\phi^{\prime}}-\frac{1}{2}\right]\left(\frac{29 \pi}{24} \leq \varphi<\frac{13 \pi}{8}\right) \\
h-\frac{h}{3}\left[1+\frac{2\left(\varphi-\phi-\phi_{s}\right)}{\phi^{\prime}}-\frac{1}{2 \pi} \sin \frac{4 \pi\left(\varphi-\phi-\phi_{s}\right)}{\phi^{\prime}}\right]\left(\frac{13 \pi}{8} \leq \varphi<\frac{11 \pi}{6}\right) \\
0\left(\frac{11 \pi}{6} \leq \varphi<2 \pi\right)
\end{array}\right.
$$




\subsection{Simulation Analysis}

\subsubsection{Modeling Constraints}

According to the design requirements, the $\mathrm{X}$ direction is the direction of the planting depth of the hole former, and the $\mathrm{Y}$ opposite direction is the direction of the forward direction of the planter to establish the simulation model of the direct insertion planter as shown in Figure 13 (Wurun, Fei, \& Jie, 2013). AB is crank, BC is connecting rod, $\mathrm{CF}$ is guide rod of cavity former, $\mathrm{DE}$ is push rod. The length of crank $\mathrm{L}_{\mathrm{AB}}=80(\mathrm{~mm})$, the length of connecting rod $\mathrm{L}_{\mathrm{BC}}=200(\mathrm{~mm}), \mathrm{L}_{\mathrm{CF}}=600(\mathrm{~mm})$, and the length of push rod $\mathrm{L}_{\mathrm{DE}}=300(\mathrm{~mm})$ create a model in ADAMS_View modular (Zengang, 2012; Wuyun, Ranran, \& Jianming, 2012), add a driver on the handle Joint_1, MOTION_1 $=180\left(\mathrm{~d} \mathrm{~s}^{-1}\right)$, add a drive on the center of the cam center, MOTION_2 = $180\left(\mathrm{~d} \mathrm{~s}^{-1}\right)$, according to the function s of cam angle and push rod displacement, use the if function to create the cam, and the cam is filled with a cam pair between the push rod and the cam (Fang \& Zhigang, 2007), the model is shown in Figure 13. The if function (Jiantuo, Wuyun, \& Yanhua, 2010b) is shown in appendix A.

\subsubsection{Simulation Analysis}

The simulation analysis of the in-line seeder is carried out to take the point MARKER_5 on the end F of the guide rod CF as the measurement object, the initial coordinate value is $(235,400,0)$, with the cam center as the coordinate center, output the displacement and speed of the MARKER_5 point.

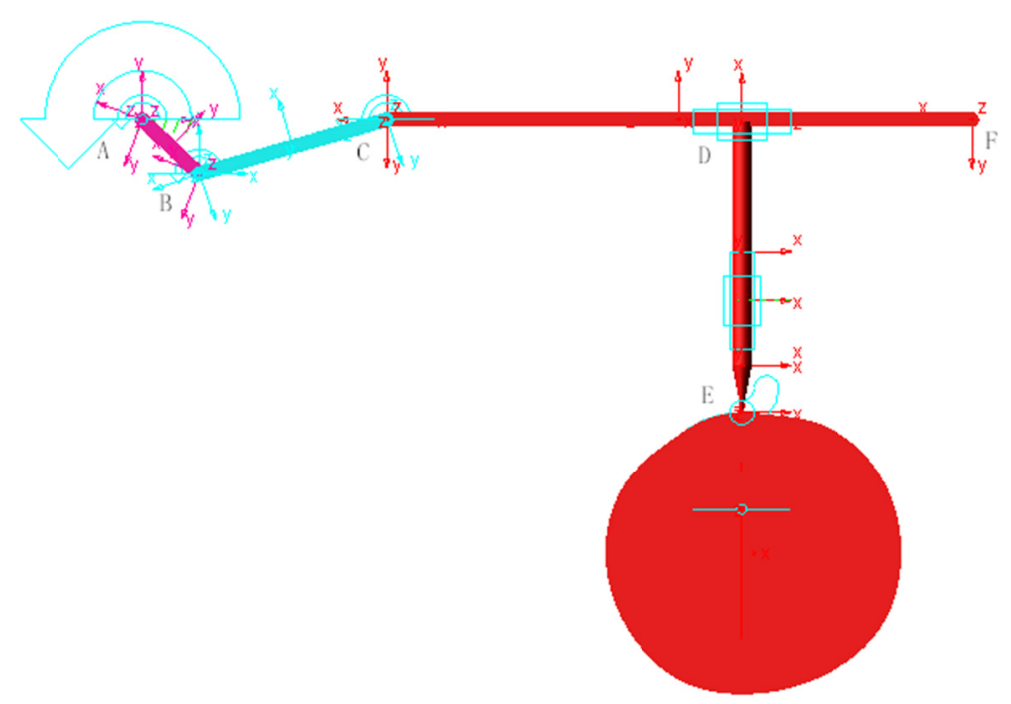

Figure 13. Simulation model of the in-line seeder

Figure 14 shows the y-direction displacement curve of marker_5, that the movement direction displacement of seed seeder. It can be seen from the curve that the maximum push rod DE displacement of cam driven is $490 \mathrm{~mm}$, and the lift is $90(\mathrm{~mm})$, which is consistent with the design requirement $90 \mathrm{~mm}$ of cam lift. Figure 15 shows the y-direction speed curve of marker_5 point, in which (0-1 s) is the cam lift stage and (1-2 s) is the cam return step break. It is measured that the vertical speed of the hole former in the soil section $(0.2-0.64 \mathrm{~s})$ and the excavated section (1.2-1.64 s) is $0.15\left(\mathrm{~m} \mathrm{~s}^{-1}\right)$, and the forward speed of the soil section and the seeder is $0.15\left(\mathrm{~m} \mathrm{~s}^{-1}\right)$, which is consistent with the speed of the seeder, and the direction is opposite, realizing the absolute speed Zero. According to Figure 16, the x-equation displacement of the seeder is measured at marker_5, that the range of sowing depth is 91 to $263.65(\mathrm{~mm})$, and the sowing depth can be changed by changing the length of the connecting rod $\mathrm{BC}$. 


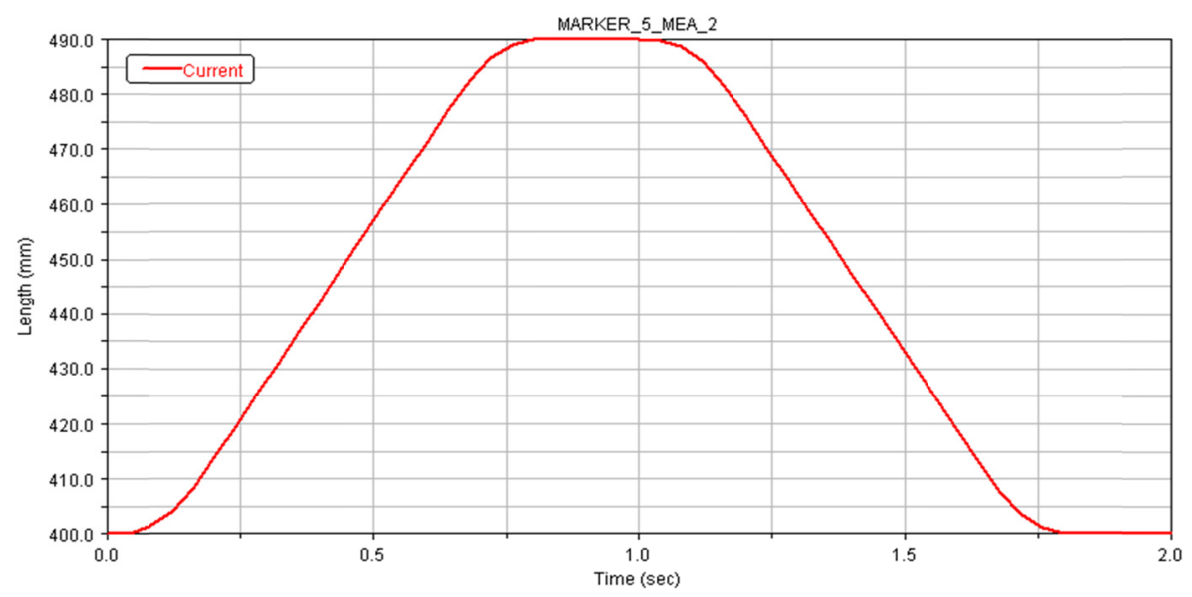

Figure 14. MARKER_5 point vertical displacement curve

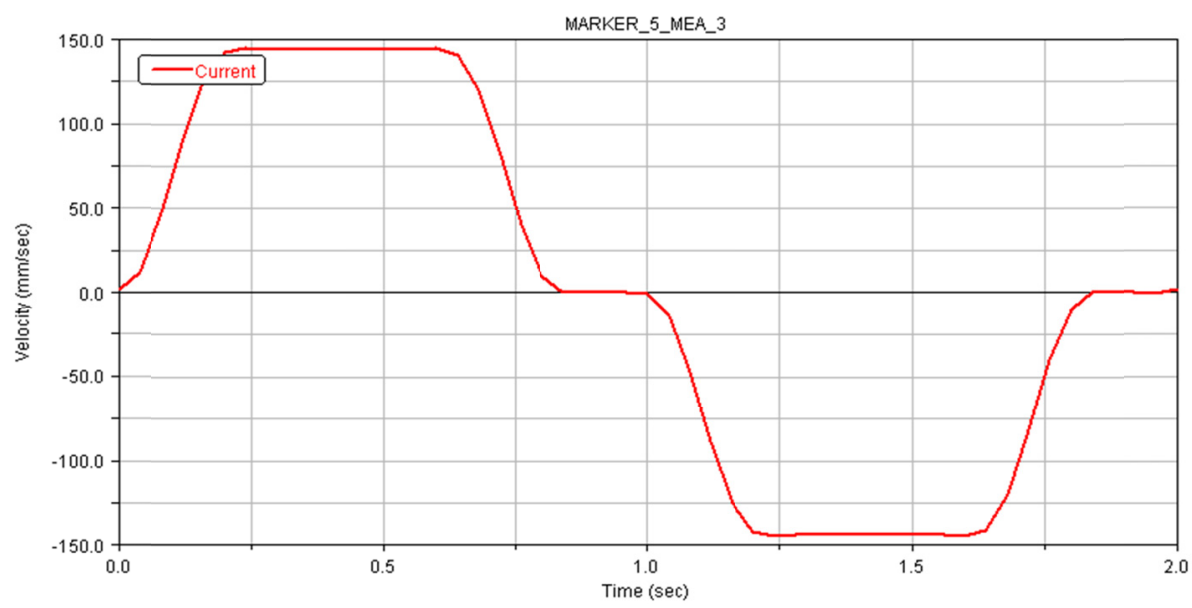

Figure 15. MARKER_5 point vertical speed curve

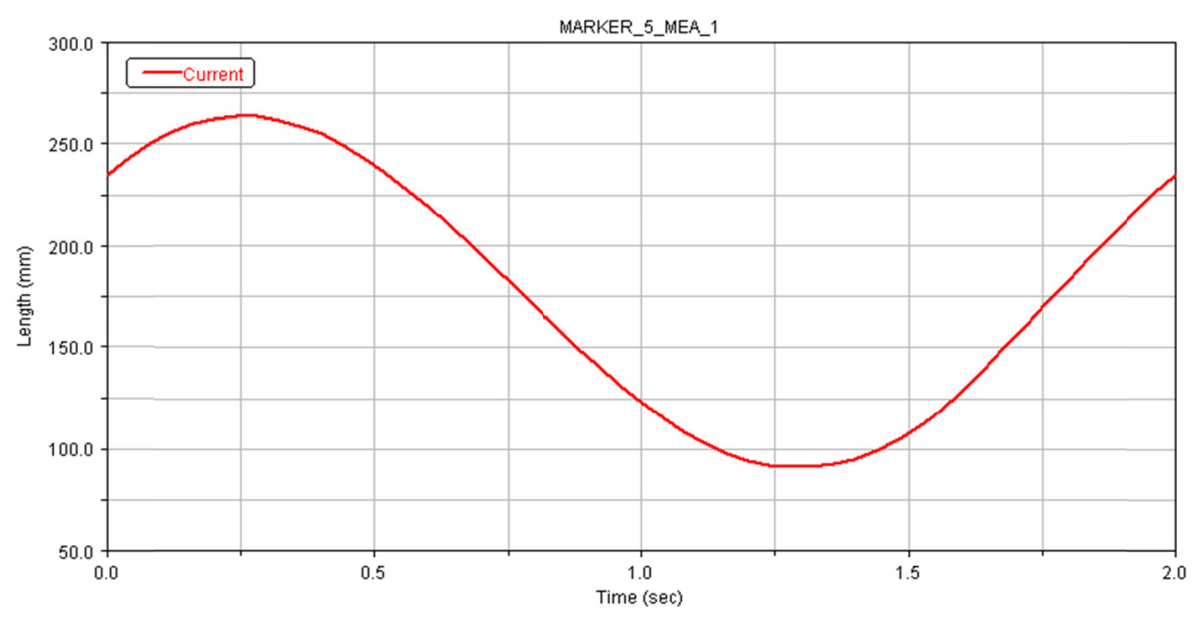

Figure 16. MARKER_5 point horizontal displacement curve

\subsubsection{Simulation Results}

The displacement and velocity curves of the hole-forming device are obtained by the curve synthesis method in ADAMS_View (Xingrui, Linrong, \& Wuyun, 2015). The simulation results show that the absolute speed is zero when seeding, which meets the requirements of direct-inserted design. 


\section{Seedling Test}

According to the on-the-spot investigation, Ginseng seedlings need to be transplanted after one year growth period during the spring or autumn of every year. Usually spring is in March to early April, and autumn is in mid-ctober to early November. Transplant is to dug up the Ginseng seedlings, eliminate rotten and disease seedlings, put the Ginseng root in oblique groove, plough a ditch as a standard of 16 to $18(\mathrm{~cm})$ depth, 7 to 10 $(\mathrm{cm})$ planting distance, 20 to $20(\mathrm{~cm})$ row distance, make the root a bit straight, then cover fully the seedling head over $7(\mathrm{~cm})$ with soil. Ginseng is cultivated and supplied mainly by farmers' homework. Due to this equipment has not been put into the market, only through manual simulation of the equipment to directly insert and sow a small area on internal plastic film for one year cultivation. Since the film can improve the growth environment of seedlings, such as moisture, epidemic prevention, weeding, etc. (Xiangwen \& Xincai, 1999); the rhizome can be kept straight, and the enough nutrients and light can be guaranteed. Compared with the traditional seedlings, its appearance, variety and weight of each seedling are better than the traditional ones. It's just practical experience, and following research is the direction of its future efforts.

\section{Economic and Social Benefits}

Acording to the Structural model and simulation results, this design increases the versatility of the machine, and it is possible to realize the seeding of different kinds of pellet seeds by simply replacing some components in the parts library. The power configuration adopts a more environmentally friendly battery driven power by a brushless motor. This can effectively reduce noise and reduce mechanical vibration compared to previous traditional farm machinery. The precision adjustment result of the hole depth and the controllable planting distance according to the speed of the vehicle shown as simulation result in this text, which can make the seeding more precise and the stronger adaptabily.

\section{Conclusion}

This research is primarily aimed at designing and researching a seeding machine with intelligent film-direct-inserted seeding type. It has a simple and reliable structure, precise seed collection, vertical speed seeding, automatic adaptation to the working environment, portable operation and cost. Low-level advantages, better service for crop planting operations, improve work efficiency and crop quality.All the selection and design work of the whole machine ensure its performance. The results have been verified by applying relevant theories in the above text, and its feasibility has been guaranteed by simulation. Anyway, it has been verified the advantages of this method of seedling breeding by hand instead of the machine in a small area. However, at present, the machine only needs to get to the model stage. The future work is to apply its privatization in field operations and at the same time. It is developing towards technology and intelligence, and finally achieves the goal of high quality and high yield of ginseng and other crops.

\section{References}

Baogang. (2010). Breeding technology of ginseng seedlings. Gansu Agricultural Science and Technology, 9.

Chenglin, M., \& Chenhua, L. (2014). Development and present situation of research on hole drill. Agricultural Machinery.

China Academy of Agricultural Mechanization Sciences. (2007). Handbook of Agricultural Machinery. Beijing: China Agricultural Science and Technology Press.

Fang, X., \& Zhigang, Z. (2007). Design and kinematics simulation of cam mechanism based on ADAMS. Machinery Design \& Manufacture, 9(9), 78-80.

Guoxun, P., \& Zhengyang, X. (1990). Design of automatic mechanical cam mechanism (pp. 37-40). Beijing: Mechanical Industry Press.

Han, Z., Jue, D., \& Jinhua, L. (1983). Design of cam mechanism. Beijing: Higher Education Press.

Hongan, W., \& Shilu, S. (2001). Vertically Inserted Wheat Film Mulching Machine. Transactions of the Chinese Society of Agricultural Machinery, 32(6), 34-37.

Jixin, W. (2013). Study on Planter with Film Spreading by Dibbling Sowing. Agricultural Development and Equipment.

Jiantuo, Z., Wuyun, Z., \& Yanhua, R. (2010a). Design and Simulation of In-line Seeding Mechanism of Corn Full-film Covered Double Ridge Ditching Machine. Transactions of the Chinese Society of Agricultural Machinery, 4l(10), 40-43. 
Jiantuo, Z., Wuyun, Z., \& Yanhua, R. (2010b). Design and simulation of direct seeding device of Double Ridge and furrow seeder covered with corn film. Journal of Agricultural Machinery, 41(10), 40-43.

Lianggui, Y., Minggang, J. (2006). Mechanical Design (Version 8). Beijing: Higher Education Press.

Linwei, S., Wuyun, Z., Wei, S., Rongbin, L., Bingbang, X., \& Fei, D. (2017). Development and experiment of direct insertion hole driller on corn membrane in electric drive type community. Transactions of the Chinese Society of Agricultural Machinery, 33(4), 32-38.

Longchang, C., Zhian, Q., \& Xinzheng, L. (2000). Controlling the motor. Xi'an: Xi'an University of Electronic Science and Technology Press.

Mengchun, G. (2012). Plastic Film Ground Cover Cultivation Technique. Jilin Agricultural.

Wei, S., \& Jianmin, W. (2009). Selection and research of duckbill-type acupoints. Journal of Gansu Agricultural University, 44(5), 140-142.

Wurun, Z., Fei, D., \& Jie, Y. (2013). Corn full film double ridge and furrow direct planting precision design and test of the hole seeder. Transactions of the Chinese Society for Agricultural Machinery, 44(11), 91-97.

Wuyun, Z., Ranran, L., \& Jianming, W. (2012). ADAMS Basic and application example tutorial. Beijing: Tsinghua University Press.

Xiangwen, X., \& Xincai, Z. (1999). Effects of mulching irrigation on soil environment and plant growth in cotton field. Journal of Xinjiang Agricultural University.

Xiaoguang, C., Chunxi, Z., \& Feng, G. (1993). Research on in-line hole-forming device for in-line seeder. Journal of Agricultural Engineering, 9(3), 66-70.

Xingrui, L., Linrong, S., \& Wuyun, Z. (2015). Full film double ridge and furrow sowing and direct planting design of the double faced cam of the device. Joural of Hunan of Hunan Agricultural University (Natural Science Edition), 1, 94-98.

Zengang, L. (2012). ADAMS introduction details and examples. Beijing: National Defense Industry Press.

Zongze, W. (2006). Guidelines and examples of mechanical structure design. Beijing: Mechanical Industry Press.

\section{Appendix A}

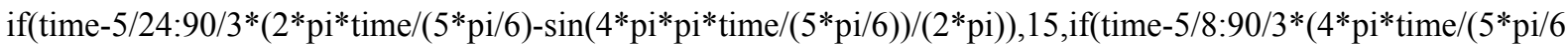
)-1/2), 75 , if(time-5/6:90/3*(1+2* pi*time/(5* pi/6)-sin( $4 * \mathrm{pi}^{*}$ pi*time/(5* pi/6))/(2* pi)), 90 , if(time-1:90,90,if(time-2 9/24:90-90/3*(2*(pi*time-5*pi/6-pi/6)/(5*pi/6)-sin $(4 *$ pi*(pi*time-5*pi/6-pi/6)/(5*pi/6))/(2* pi)), 75, if(time-13/8: 90-90/3*(4*(pi*time-5*pi/6-pi/6)/(5*pi/6)-1/2),15,if(time-11/6:90-90/3*(1+2*(pi*time-5*pi/6-pi/6)/(5* pi/6)-sin( $4 * \mathrm{pi}^{*}(\mathrm{pi} *$ time- $\left.\left.5 * \mathrm{pi} / 6-\mathrm{pi} / 6) /(5 * \mathrm{pi} / 6)\right) /(2 * \mathrm{pi})\right), 0$, if(time- $\left.\left.\left.\left.\left.\left.\left.\left.2: 0,0,0\right)\right)\right)\right)\right)\right)\right)\right)$

\section{Copyrights}

Copyright for this article is retained by the author(s), with first publication rights granted to the journal.

This is an open-access article distributed under the terms and conditions of the Creative Commons Attribution license (http://creativecommons.org/licenses/by/4.0/). 